EXTENDED REPORT

\title{
Short course prednisolone for adhesive capsulitis (frozen shoulder or stiff painful shoulder): a randomised, double blind, placebo controlled trial
}

\author{
R Buchbinder, J L Hoving, S Green, S Hall, A Forbes, P Nash
}

Ann Rheum Dis 2004;63:1460-1469. doi: 10.1136/ard.2003.018218

See end of article for authors' affiliations

\section{Correspondence to:} Associate Professor R Buchbinder, Department of Clinical Epidemiology, Suite 41 Cabrini Medical Centre, 183 Wattletree Rd, Malvern, Victoria,

Australia 3144; rachelle. buchbinder@med.monash. edu.au

Accepted 18 January 2004

\begin{abstract}
Objective: To determine whether a short course of prednisolone is superior to placebo for improving pain, function, and range of motion in adhesive capsulitis.

Design: Double blind, randomised, placebo controlled trial.

Setting: Community based rheumatology practice in Australia

Participants 50 participants (24 active, 26 placebo); 46 completed the 12 week protocol. Entry criteria were age $\geqslant 18$ years, pain and stiffness in predominantly one shoulder for $\geqslant 3$ weeks, and restriction of passive motion by $>30^{\circ}$ in two or more planes.

Interventions: $30 \mathrm{mg}$ oral prednisolone/day for three weeks or placebo.

Main outcome measures: Overall, night, and activity related pain, SPADI, Croft shoulder disability questionnaire, DASH, HAQ, SF-36, participant rated improvement, and range of active motion measured at baseline and at 3,6 , and 12 weeks.

Results: At 3 weeks, there was greater improvement in overall pain in the prednisolone group than in the placebo group (mean (SD) change from baseline, 4.1 (2.3) v 1.4 (2.3); adjusted difference in mean change between the two groups, $2.4(95 \% \mathrm{Cl}, 1.1$ to 3.8$))$. There was also greater improvement in disability, range of active motion, and participant rated improvement (marked or moderate overall improvement in 22/23 $\vee 11 / 23 ; R R=2$ (1.3 to 3.1), $p=0.001)$. At 6 weeks the analysis favoured the prednisolone group for most outcomes but none of the differences was significant. At 12 weeks, the analysis tended to favour the placebo group.

Conclusions: A three week course of $30 \mathrm{mg}$ prednisolone daily is of significant short term benefit in adhesive capsulitis but benefits are not maintained beyond six weeks.
\end{abstract}

A dhesive capsulitis (also termed frozen shoulder, stiff painful shoulder, or periarthritis) is a common cause of shoulder pain estimated to affect $2-5 \%$ of the general population. ${ }^{12}$ The cumulative incidence of presentations to general practice from a Dutch study of shoulder complaints has been estimated to be $2.4 / 1000 /$ year (95\% confidence interval (CI), 1.9 to 2.9). ${ }^{3}$ Duplay first described a condition of painful stiffening of the shoulder in $1872 .{ }^{4}$ Since then other terms have been used to label this condition, including "frozen shoulder" coined by Codman (to describe painful restriction of range of motion of the shoulder with normal plain $x$ rays $),{ }^{5}$ and "adhesive capsulitis" coined by Neviaser (based upon shoulder joint arthrographic findings). ${ }^{6}$

The disorder is characterised by spontaneous onset of shoulder pain and progressive global stiffness of the glenohumeral joint accompanied by significant disability. ${ }^{7}$ Most studies have suggested a self limiting condition lasting an average of two to three years, although significant numbers of people have residual clinically detectable restriction of movement beyond three years, and smaller numbers have residual disability. ${ }^{7-14}$

Many interventions have been advocated for the treatment of adhesive capsulitis, although only limited data from randomised controlled trials are available. ${ }^{15}$ After systematically reviewing the evidence, we previously concluded that there were not enough data to either support or refute the efficacy of any of the commonly used interventions for this condition, including non-steroidal anti-inflammatory drugs, corticosteroid injections, and physiotherapy, and further well designed clinical trials were needed. ${ }^{15}$ Oral steroids were first advocated in the 1950s, with claims that they expedited recovery and reduced the need for manipulation under anaesthesia. ${ }^{16-18}$ Since then there have been three published randomised trials of oral steroids for adhesive capsulitis. ${ }^{19-21}$ These are described in table 1 .

Based upon the results of these three trials, it is not possible to draw firm conclusions about the efficacy of oral steroids in adhesive capsulitis, although two studies have suggested a more rapid improvement in pain. ${ }^{19}{ }^{21}$ Possible reasons for the failure to show a substantial beneficial effect of oral steroids in previous studies may be the small sample sizes (and hence no consideration of type II error), the relatively low doses of prednisolone used, and administration too late in the course of the disease. In addition, participants were not blinded in one trial ${ }^{21}$ and participants who were not improving received manipulation under anaesthesia in another trial. ${ }^{19}$ Oral prednisolone dramatically ameliorates the symptoms of inflammatory joint diseases such as rheumatoid arthritis. ${ }^{22}$ It is therefore reasonable to suppose that oral prednisolone may be effective in adhesive capsulitis, particularly early in the course of the disease.

The aims of our study were first, to determine whether a three week course of oral prednisolone, $30 \mathrm{mg}$ daily, in patients with adhesive capsulitis of at least three weeks' duration is superior to placebo for improving pain, function, and range of motion at three weeks; and second, to determine whether benefit is maintained at six and 12 weeks.

Abbreviations: DASH, disabilities arm shoulder and hand; $H A Q$, health assessment questionnaire; SF-36, short form 36 item health survey; SPADI, shoulder pain and disability index 
Table 1 Description of published randomised controlled trials of oral corticosteroids for adhesive capsulitis

\begin{tabular}{|c|c|c|c|c|}
\hline Author, year & $\begin{array}{l}\text { Sample } \\
\text { size }\end{array}$ & Active intervention & $\begin{array}{l}\text { Control } \\
\text { intervention }\end{array}$ & Results \\
\hline $\begin{array}{l}\text { Blockey and } \\
\text { Wright, } 1954^{19}\end{array}$ & 32 & $\begin{array}{l}\text { Cortisone acetate }(200 \mathrm{mg} \\
\text { daily for } 3 \text { days, then } 100 \mathrm{mg} \\
\text { daily for } 11 \text { days, then dose } \\
\text { tapered off in decrements of } \\
12.5 \mathrm{mg} \text { every } 2 \text { days, total } \\
\text { dose }=2.5 \mathrm{~g} \text { over } 4 \text { weeks. If } \\
\text { unsatisfactory progress after } \\
4 \text { weeks, manipulation under } \\
\text { general anaesthesia; followed } \\
\text { by a second four week course } \\
\text { of cortisone acetate. }\end{array}$ & Placebo & $\begin{array}{l}\text { No statistical analysis of between-group differences reported, although } \\
\text { an earlier clinically important improvement in both pain and range of } \\
\text { movement was noted in the oral steroid group: mean pain scores } \\
\text { (measured on a } 4 \text {-point categorical scale converted into an interval scale, } \\
\text { where none }=0 \text {, slight }=1 \text {, moderate }=2 \text {, severe }=3 \text { ) at baseline, } 1,4, \\
\text { and } 18 \text { weeks were } 1.4,0.9,0.5,0.6 \text { in the steroid group, and } 1.4,1.3 \text {, } \\
0.8,0.5 \text { in the control group; total shoulder abduction was } 82^{\circ}, 103^{\circ} \text {, } \\
125^{\circ}, 153^{\circ} \text { in the steroid group, and } 75^{\circ}, 89^{\circ}, 106^{\circ}, 154^{\circ} \text { in the control } \\
\text { group. The number of participants requiring manipulation after four } \\
\text { weeks was } 6 / 15(40 \%) \text { and } 11 / 16(68.8 \%) \text { in the steroid and placebo } \\
\text { groups, respectively (RR }=0.58(0.29 \text { to } 1.17) \text {. }\end{array}$ \\
\hline $\begin{array}{l}\text { Kessel et al, } \\
1981^{20}\end{array}$ & 32 & $\begin{array}{l}\text { Prednisolone ( } 15 \mathrm{mg} \text { daily } \\
\text { for } 4 \text { weeks) and manipulation } \\
\text { (after } 2 \text { weeks of oral steroids) }\end{array}$ & $\begin{array}{l}\text { Manipulation } \\
\text { alone }\end{array}$ & $\begin{array}{l}\text { No statistical analysis was done but "dramatic response" to manipulation } \\
\text { in } 7 / 12(58.3 \%) \text { participants taking oral steroid compared with } 5 / 16 \\
(31.25 \%) \text { participants taking placebo. Effect of manipulation on final } \\
\text { range of movement at } 6,12 \text {, and } 18 \text { weeks following the procedure also } \\
\text { favoured the steroid group but again the differences between groups } \\
\text { were not formally analysed. }\end{array}$ \\
\hline $\begin{array}{l}\text { Binder et al, } \\
1986^{21}\end{array}$ & 40 & $\begin{array}{l}\text { Prednisolone ( } 10 \mathrm{mg} \text { daily } \\
\text { for four weeks, then } 5 \mathrm{mg} \\
\text { daily for two weeks) }\end{array}$ & No treatment & $\begin{array}{l}\text { The pattern of improvement in pain at night over } 8 \text { weeks showed a } \\
\text { significant difference in favour of oral prednisolone with a more rapid } \\
\text { initial recovery, although by } 5 \text { months the difference between the groups } \\
\text { was negligible. Improvement in pain at rest and with movement, range of } \\
\text { motion, and a cumulative recovery curve were not significantly different } \\
\text { between groups over } 8 \text { months. }\end{array}$ \\
\hline
\end{tabular}

\section{METHODS}

\section{Study design and treatment assignment}

We carried out a randomised, placebo controlled trial between 1996 and 2000. Consenting participants were randomised by computer generated permuted block randomisation of 8 to receive either $30 \mathrm{mg}$ oral prednisolone or placebo daily for three weeks. ${ }^{23}$ Allocation concealment was ensured and the study biostatistician kept the assignment scheme. Participants and treating physicians were blinded to treatment allocation. An independent trained outcome assessor, also blinded to treatment allocation, evaluated the participants at baseline and at three, six, and 12 weeks. The Cabrini Hospital ethics committee granted ethical approval.

\section{Study participants}

We recruited study participants from the general practice referral base of the community based rheumatology practices of three of the investigators ( $\mathrm{RB}, \mathrm{SH}, \mathrm{PN})$. Inclusion criteria were:

- pain and stiffness in one shoulder predominantly for three weeks or more;

- restriction of passive motion by more than $30^{\circ}$ in two or more planes of movement, measured to the onset of pain with a gravity inclinometer;

- age over 18 years.

Exclusion criteria were: systemic inflammatory joint disease (including rheumatoid arthritis and polymyalgia rheumatica); oral steroids in the previous three months; diabetes mellitus (because of the potential for unblinding); pregnancy; contraindications to oral steroids including peptic ulceration, serious infection, or uncontrolled hypertension; radiological evidence of osteoarthritis of the shoulder or fracture; calcification about the shoulder joint; reason to suspect a complete rotator cuff tear (weakness of arm elevation, a positive "drop arm sign", a high riding humerus visible on $x$ ray of the shoulder or demonstration of a complete rotator cuff tear on ultrasound); and likely not to comply with follow up (for example, living too far away to attend for follow up assessment, or indicating they would be unable or unwilling to attend for outcome assessment) or lack of written informed consent.

\section{Interventions}

The active group received $30 \mathrm{mg}$ of oral prednisolone (six $5 \mathrm{mg}$ tablets) daily for three weeks, as a single morning dose. The placebo group received placebo tablets (six tablets, identical in appearance and taste to the prednisolone tablets) daily for three weeks, also as a single morning dose.

Participants in both groups received a simple exercise programme comprising pendular exercises and scapular setting (isometric scapular retraction). Participants were asked to cease non-steroidal anti-inflammatory drugs but were allowed paracetamol and codeine preparations. No other interventions-including intra-articular steroid injections, arthrographic joint distension, physiotherapy, massage, chiropractice, or manipulation under anaesthesia-were allowed for the duration of the trial. However, for ethical reasons, if the participant had not improved after six weeks, the treating physician could request unblinding of treatment allocation and further management of the condition at their discretion. This was considered a protocol violation but the participant continued to be followed up and the outcome assessor remained blinded. Although these participants received additional treatment because of the inefficacy of the study preparation, they were analysed according to their allocated treatment group.

\section{Outcome assessment}

A blinded outcome assessor evaluated all participants at baseline and at three, six, and 12 weeks. Data collected at baseline involved personal details and clinical characteristics including duration of symptoms, severity of the condition, and previous treatment. If not already available, an $x$ ray of the shoulder was obtained to ensure the participant met the selection criteria.

\section{Pain perception}

Participants' overall assessment of pain, night pain, and activity related pain were each measured using a vertical Likert scale labelled "no pain" $(=0)$ at the bottom and "maximum imaginable pain" $(=10)$ at the top.

\section{Disability assessment}

The shoulder pain and disability index (SPADI) is a self administered, shoulder specific, fixed item index consisting 
of 13 items divided into two subscales: pain (five items) and disability (eight items). ${ }^{24}$ Responses to each item were recorded on a 10 point Likert scale, where $0=$ "no pain" or "no difficulty" and $9=$ "worst imaginable pain" or "so difficult it required help" for the pain and disability items, respectively. The SPADI score is calculated by summing and then averaging the items of the two subscales to give a score out of 100 (higher scores reflects more pain/disability). The SPADI has acceptable test-retest reliability (intraclass correlation coefficients of 0.91 and 0.65 (95\% CI, 0.42 to 0.8 ) in surgical and primary care populations respectively $y^{25}$ ) and acceptable responsiveness. ${ }^{26}$

The Croft is a 22 item self administered shoulder disability questionnaire developed from the Functional Limitations Profile with input from patients with shoulder pain, physiotherapists, and occupational therapists. ${ }^{27}$ Responses to each item are recorded as a yes or a no, and the number of positive responses is summated to give a score out of 22 (a higher score reflects more disability).

The "disabilities arm shoulder and hand" (DASH) questionnaire was developed to evaluate disability and symptoms in single or multiple disorders of the upper limb at one or more points in time. ${ }^{28}$ Using a self report system, patients attribute scores to 30 items relating to functional activities and symptoms. The score is expressed as a percentage score (0-100).

The health assessment questionnaire (HAQ) is a well validated, 19 item, arthritis specific functional assessment measure and asks about two or three fixed items in eight areas of daily life. ${ }^{29}{ }^{30}$ The disability score is between 0 (no disability) and 3 (highest disability).

The short form 36 item health survey (SF-36) is a widely used, self administered, 36 item generic indicator of health status which consists of eight subscales representing eight dimensions of quality of life: physical function, role limitations because of physical health problems, bodily pain, general health perceptions, vitality, social functioning, role limitations because of emotional problems, and general mental health. ${ }^{31}$ Each of the eight subscales is rescaled from 0-100; higher scores represent better health.

\section{Improvement}

Participant-rated improvement compared with baseline was measured at three, six, and 12 weeks using a five point categorical scale (marked improvement, moderate improvement, the same, moderate worsening, marked worsening). A

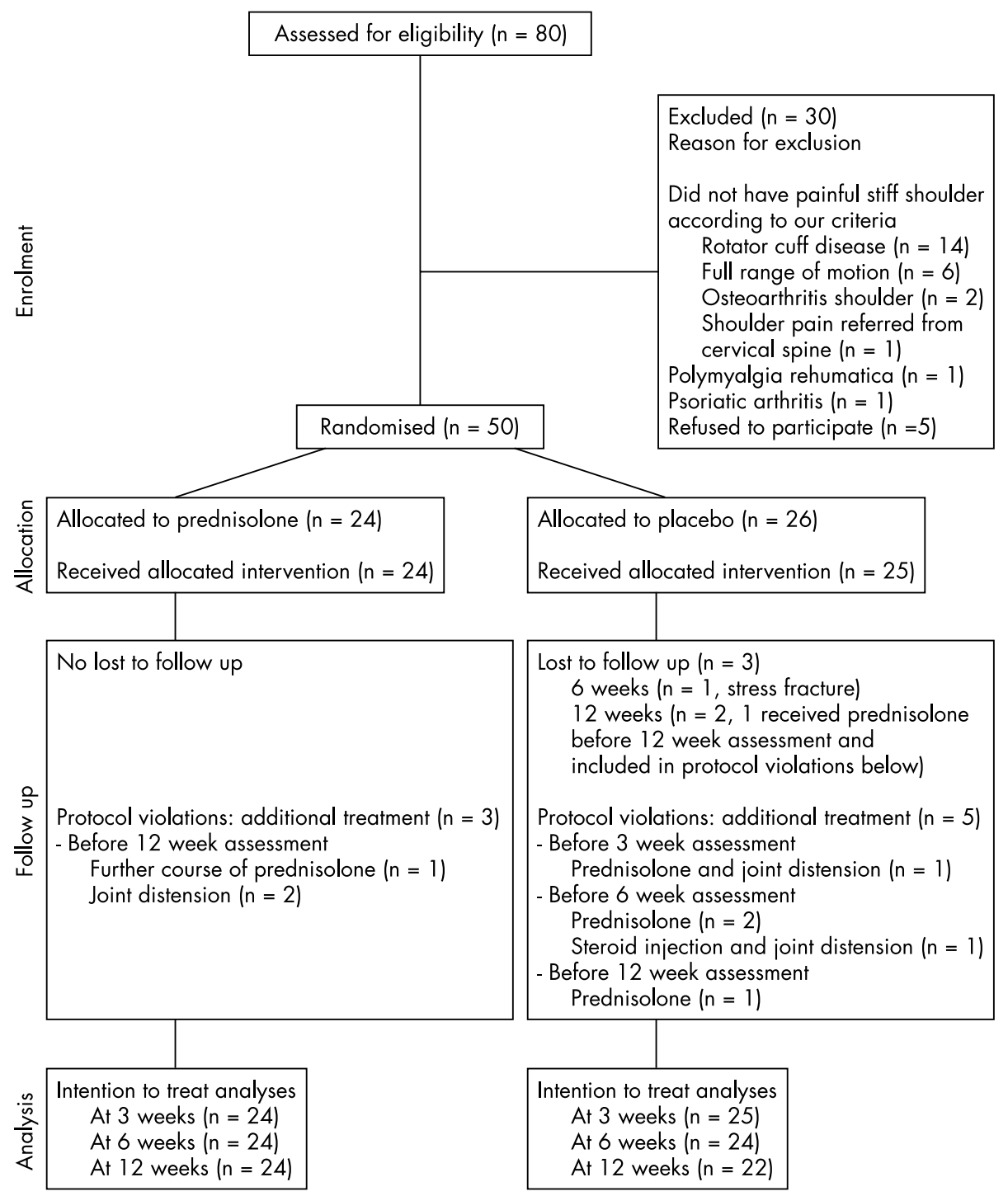

Figure 1 Flow of participants through each stage of the randomised trial. 
priori, "success" was defined as marked or moderate improvement.

\section{Range of active motion}

A standardised protocol was used to measure active total shoulder flexion and abduction (that is, scapular and glenohumeral movement combined) and external glenonohumeral rotation in neutral abduction, using an inclinometer; hand behind back was measured by assessment of the anatomical landmark reached by the extended thumb. ${ }^{32}$ This method has been shown to have high intrarater reliability (intraclass correlation coefficients of 0.75 to 0.93 ). ${ }^{32}$

\section{Adverse effects}

Adverse effects of the intervention were elicited by the use of open ended questions.

\section{Sample size and power}

The primary outcome measure, determined before the start of the trial, was overall pain perception at three weeks. Based upon a previous study which used rest pain as an outcome and displayed box plots of the differences between the active and placebo group, we estimated that participants randomised to receive placebo treatment would have a mean pain score of 8 (on a scale 0 to 10 ) after three weeks of treatment. ${ }^{21}$ Assuming that the standard deviation is 2, we determined that a sample size of 21 participants per group would have $90 \%$ power at a significance level of 0.05 to detect a clinically important difference in pain perception of 2. Sample size was increased to 25 per group to allow for dropouts.

\section{Data analysis}

All analyses were done with SPSS for Windows, version 11.5 (SPSS, Chicago, Illinois, USA). All analyses were planned on an intention to treat principle using all randomised patients who provided any post-baseline data. Demographic characteristics of the active and placebo groups were summarised by descriptive statistics. Analysis of covariance (ANCOVA) was undertaken using the follow up data at three, six, and 12 weeks for each of the patient rated outcomes, with adjustment for the baseline values of the outcome of interest. ${ }^{33}$ An overall repeated measures analysis of covariance adjusting for baseline values was also used to assess whether the difference between treatment groups was constant over time. If no evidence of differences in treatment effect across time was found at the $5 \%$ significance level, a pooled difference between groups across all time points was calculated. Relative risks and risk differences were calculated as ratios of success rates and differences in success rates for perceived recovery, respectively.

\section{RESULTS}

Eighty potential participants were screened and 50 recruited. Participants moved through the trial as outlined in fig 1 . Data were available for intention to treat analysis on all 24 participants in the active group for all time points, and for 25 , 24 , and 22 participants in the placebo group at three, six, and 12 weeks, respectively.

There were eight known protocol violations resulting from the provision of additional treatment (three participants in the active group and five in the placebo group (fig l)). One participant in the placebo group discontinued study medication before the end of the three week course of treatment and was given prednisolone and subsequently an arthrographic joint distension with saline and steroid. Three participants in the placebo group received additional treatment before the six week assessment: two received prednisolone and one was treated with a corticosteroid injection and subsequently an arthrographic joint distension with saline and steroid. Four participants (three in the active group and one in the placebo group) received additional treatment before the 12 week assessment: one placebo treated participant received prednisolone and one participant in the active group received a further course of prednisolone; two participants in the active group had an arthrographic joint distension with saline and steroid. One participant in the placebo group who received prednisolone after the six week assessment did not return for the 12 week assessment.

Table 2 shows the demographic and outcome variables of the active and placebo groups at baseline. Apart from sex, there were no baseline differences of clinical importance between the two groups for any of the demographic or clinical characteristics examined. The placebo group had more women (83\%) than the active group (57\%) but analyses adjusted for sex showed similar results, so only results adjusted for the baseline values of the outcome measure of interest are presented.

Mean changes from baseline for pain, disability, and range of motion measures for both groups for all time points, and with the baseline-adjusted between-group differences of that change, are presented in table 3. At three weeks, there was a significantly greater improvement in overall pain in the prednisolone group than in the placebo group (mean (SD) change from baseline $=4.1(2.3)$ and $1.4(2.3)$ in the active and placebo groups, respectively; adjusted difference in mean change between the two groups $=2.4$ (95\% CI, 1.1 to 3.8$)$ ) . This difference was considered clinically important according to our predefined criteria ( 2 points on a $0-10$ point scale). There was also a significantly greater improvement in night and movement pain, disability (as measured by SPADI, Croft,

\begin{tabular}{|c|c|c|}
\hline Variable & $\begin{array}{l}\text { Oral prednisolone } \\
(n=24)\end{array}$ & $\begin{array}{l}\text { Placebo } \\
(n=25)\end{array}$ \\
\hline Age (years) & $53.5(5.1)$ & $55.0(9.0)$ \\
\hline Female & $20(83.3 \%)$ & $15(60.0 \%)$ \\
\hline History of shoulder trauma & $5(21.7 \%)$ & $4(16.0 \%)$ \\
\hline Left shoulder affected & $12(52.2 \%)$ & $14(56.0 \%)$ \\
\hline \multicolumn{3}{|c|}{ Previous treatment for shoulder pain } \\
\hline Steroid injections & 3 & 4 \\
\hline Hydrodilatation & 3 & 1 \\
\hline Physiotherapy & 2 & 3 \\
\hline Manipulation under anaesthesia & 0 & 1 \\
\hline Duration of symptoms (weeks) & 25.5 (13.3) & $21.1(13.8)$ \\
\hline Severity (out of 10) & $7.7(1.5)$ & $7.4(1.8)$ \\
\hline SPADI score $(0-100)$ & $64.7(14.1)$ & $60.5(19.3)$ \\
\hline Croft score $(0-21)$ & $12.8(4.1)$ & $11.5(3.6)$ \\
\hline \multicolumn{3}{|l|}{ Problem elicitation technique } \\
\hline score $(0-\infty)$ & $160.0(71.5)$ & $158.7(76.7)$ \\
\hline \multicolumn{3}{|l|}{ Pain score $(0-10)$} \\
\hline Overall & $7.3(1.4)$ & $6.8(1.8)$ \\
\hline At night & $7.5(2.3)$ & $6.8(2.1)$ \\
\hline During activity & $7.9(1.4)$ & $7.9(1.4)$ \\
\hline DASH $(0-100)$ & $45.0(16.0)$ & $40.2(17.5)$ \\
\hline HAQ disability (0-3) & $1.4(0.9)$ & $1.1(0.6)$ \\
\hline \multicolumn{3}{|l|}{ Range of motion (degrees) } \\
\hline Total shoulder flexion & $82.9(29.4)$ & $93.2(29.5)$ \\
\hline Total shoulder abduction & $60.0(26.0)$ & $70.2(25.3)$ \\
\hline External rotation in neutral & $27.3(22.8)$ & $30.0(28.9)$ \\
\hline \multicolumn{3}{|l|}{ SF-36 } \\
\hline Physical function & $57.7(21.0)$ & $60.4(22.8)$ \\
\hline Role physical & $25.0(38.3)$ & $27.0(35.3)$ \\
\hline Bodily pain & $31.7(16.1)$ & $37.1(18.6)$ \\
\hline General health & $65.8(22.0)$ & $68.6(18.9)$ \\
\hline Vitality & $42.0(26.3)$ & $46.4(18.0)$ \\
\hline Social function & $72.0(26.1)$ & $67.5(29.1)$ \\
\hline Role emotion & $51.3(47.1)$ & $62.6(42.3)$ \\
\hline Mental health & 63.3 (17.6) & $64.8(21.2)$ \\
\hline
\end{tabular}

Values are mean $(S D), n$, or $n(\%)$.

SPADI, shoulder pain and disability index. 


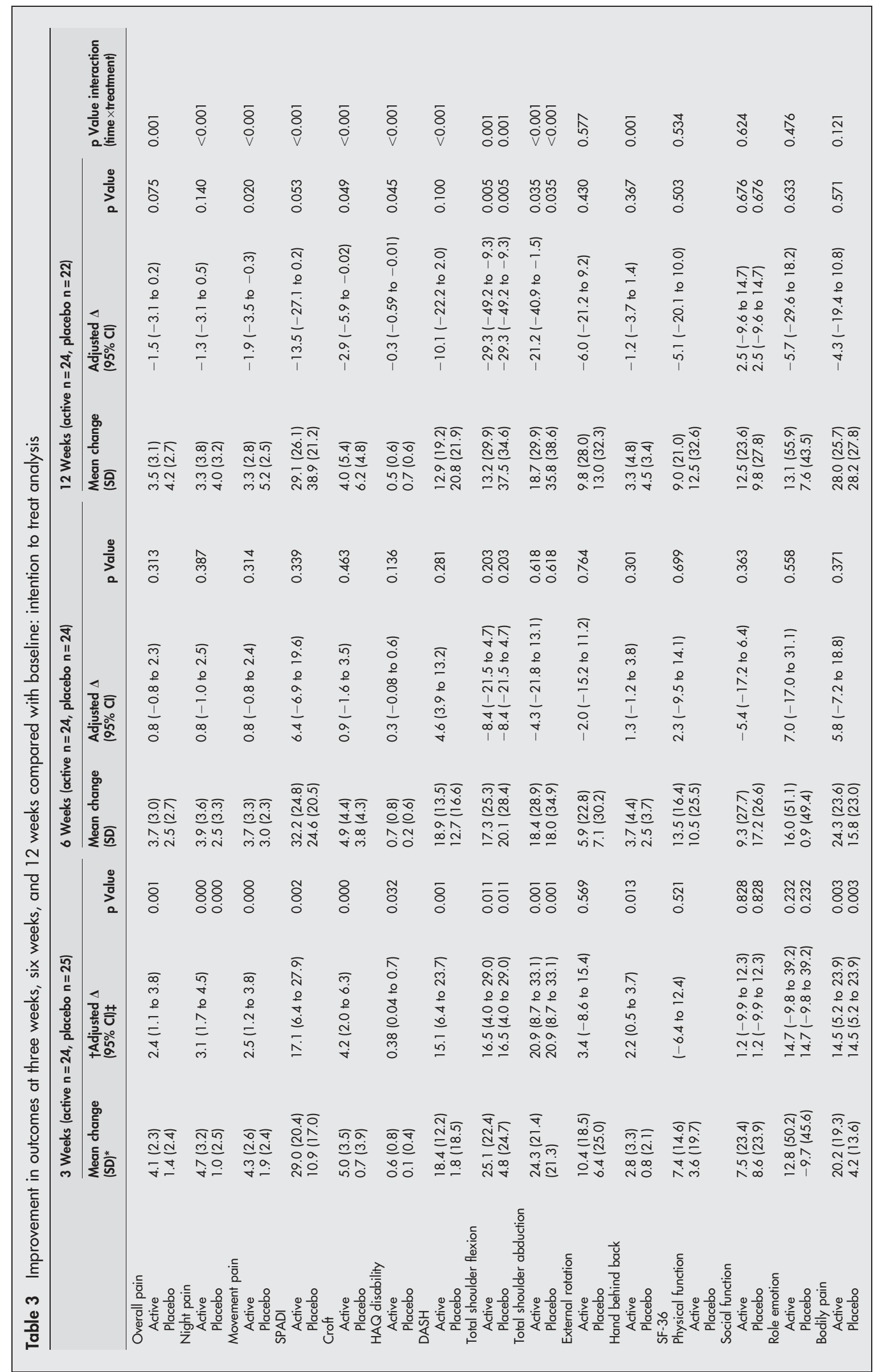




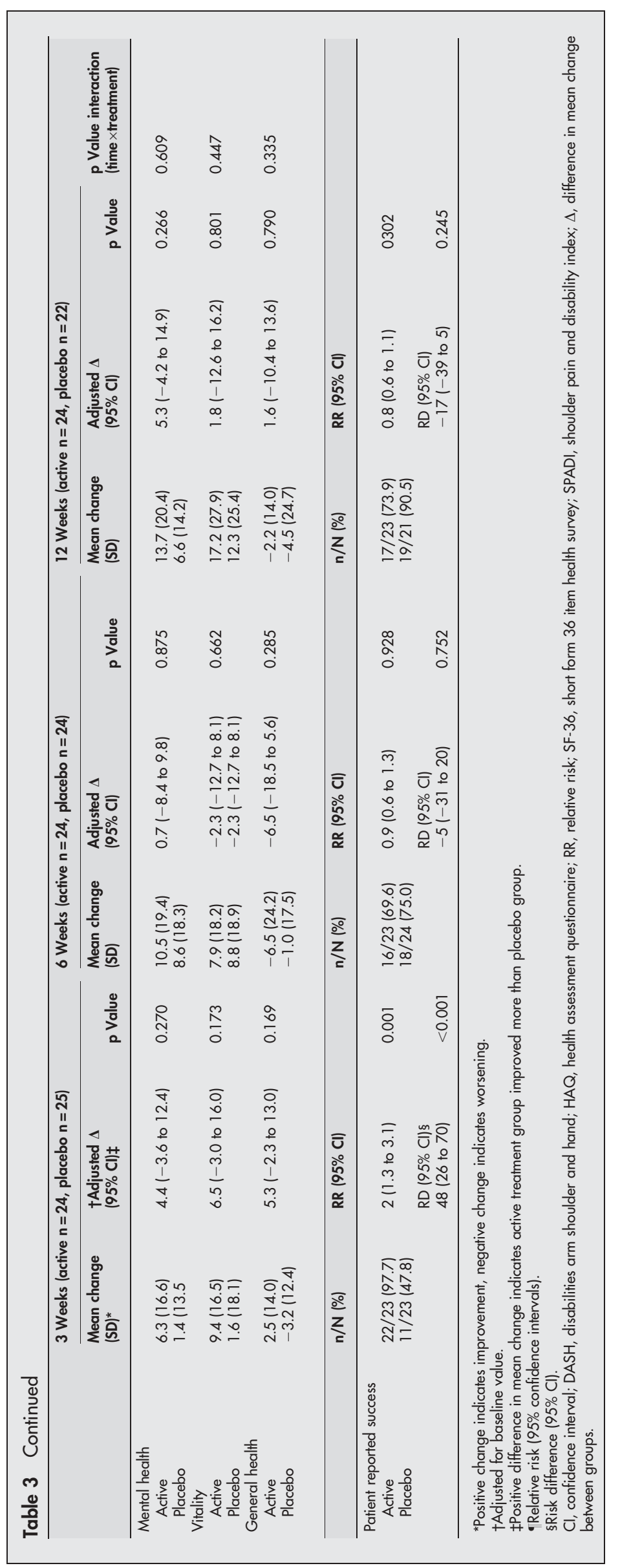

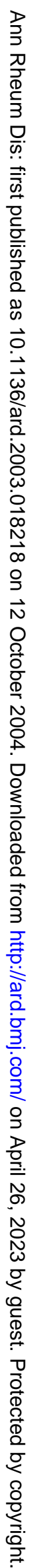


Table 4 Results for the eight participants who received additional treatment during the trial

\begin{tabular}{|c|c|c|c|c|c|c|c|c|c|c|}
\hline \multirow[b]{2}{*}{ Subject } & \multirow{2}{*}{$\begin{array}{l}\text { Timing of withdrawal } \\
\text { with respect to } \\
\text { assessments (between } \\
\text { weeks) }\end{array}$} & \multirow[b]{2}{*}{ Co-intervention } & \multicolumn{4}{|c|}{ Overall pain in week: } & \multicolumn{4}{|c|}{ SPADI in week: } \\
\hline & & & 0 & 3 & 6 & 12 & 0 & 3 & 6 & 12 \\
\hline \multicolumn{11}{|l|}{ Active } \\
\hline Participant 1 & $6-12$ & Joint distension & 8 & 8 & 7 & 5 & 50 & 70 & 59 & 53 \\
\hline Participant 2 & $6-12$ & Joint distension & 8 & 5 & 6 & 2 & 78 & 62 & 64 & 8 \\
\hline Participant 3 & $6-12$ & Second course prednisolone & 8 & 5 & 5 & 2 & 68 & 61 & 61 & 44 \\
\hline \multicolumn{11}{|l|}{ Placebo } \\
\hline Participant 4 & $0-3$ & $\begin{array}{l}\text { Prednisolone followed by joint } \\
\text { distension }\end{array}$ & 10 & 3 & 1 & 0 & 74 & 27 & 29 & 2 \\
\hline Participant 5 & $3-6$ & Prednisolone & 8 & 8 & 2 & 5 & 80 & 84 & 26 & 46 \\
\hline Participant 6 & $3-6$ & Prednisolone & 8 & 9 & 5 & 1 & 63 & 60 & 28 & 7 \\
\hline Participant 7 & $3-6$ & $\begin{array}{l}\text { Steroid injection followed by joint } \\
\text { distension }\end{array}$ & 8 & 5 & 3 & 2 & 70 & 59 & 25 & 16 \\
\hline Participant 8 & $6-12$ & Prednisolone & 9 & 8 & 8 & - & 87 & 78 & 70 & - \\
\hline
\end{tabular}

DASH, HAQ, and the bodily pain subscale of SF-36), active total shoulder abduction and flexion, and hand behind back in participants in the prednisolone group compared with the placebo group. The proportion of participants who reported marked or moderate overall improvement also favoured the steroid group $(22 / 23 v 11 / 23$ in the placebo group, relative risk $(\mathrm{RR})=2(95 \% \mathrm{CI}, 1.3$ to 3.1$), \mathrm{p}=0.001$; risk difference $=48 \%$ ( $26 \%$ to $70 \%), p<0.001)$.

At six weeks, the intention to treat analysis still favoured the prednisolone group for most outcomes measured (except total active shoulder flexion and external rotation in neutral) but none of the differences reached statistical significance. An alternative analysis omitting the four participants who received additional treatment before the six week assessment accentuated the trend favouring the prednisolone group but again none of the differences reached statistical significance (data not shown).

At 12 weeks, the intention to treat analysis favoured the placebo group, but compared with the three week differences between groups the differences between groups were more modest and only achieved borderline statistical significance for movement pain, Croft index, HAQ disability, and active total shoulder flexion and abduction. An alternative analysis omitting the eight participants who received additional treatment before the 12 week assessment (five in the placebo group and three in the active group) did not appreciably alter the results (data not shown).

Table 4 presents the raw data at each time point for overall pain and SPADI for the eight participants who received additional treatment during the course of the trial. All eight participants improved substantially according to all assessed measures following provision of additional treatment.

For none of the outcomes except external rotation in neutral was the difference between treatment groups constant over time, as indicated by significant $\mathrm{p}$ values for interaction (time $\times$ treatment) (table 3 ). This can be appreciated by inspection of the data displayed graphically (fig 2). While both groups improved during the course of the trial,

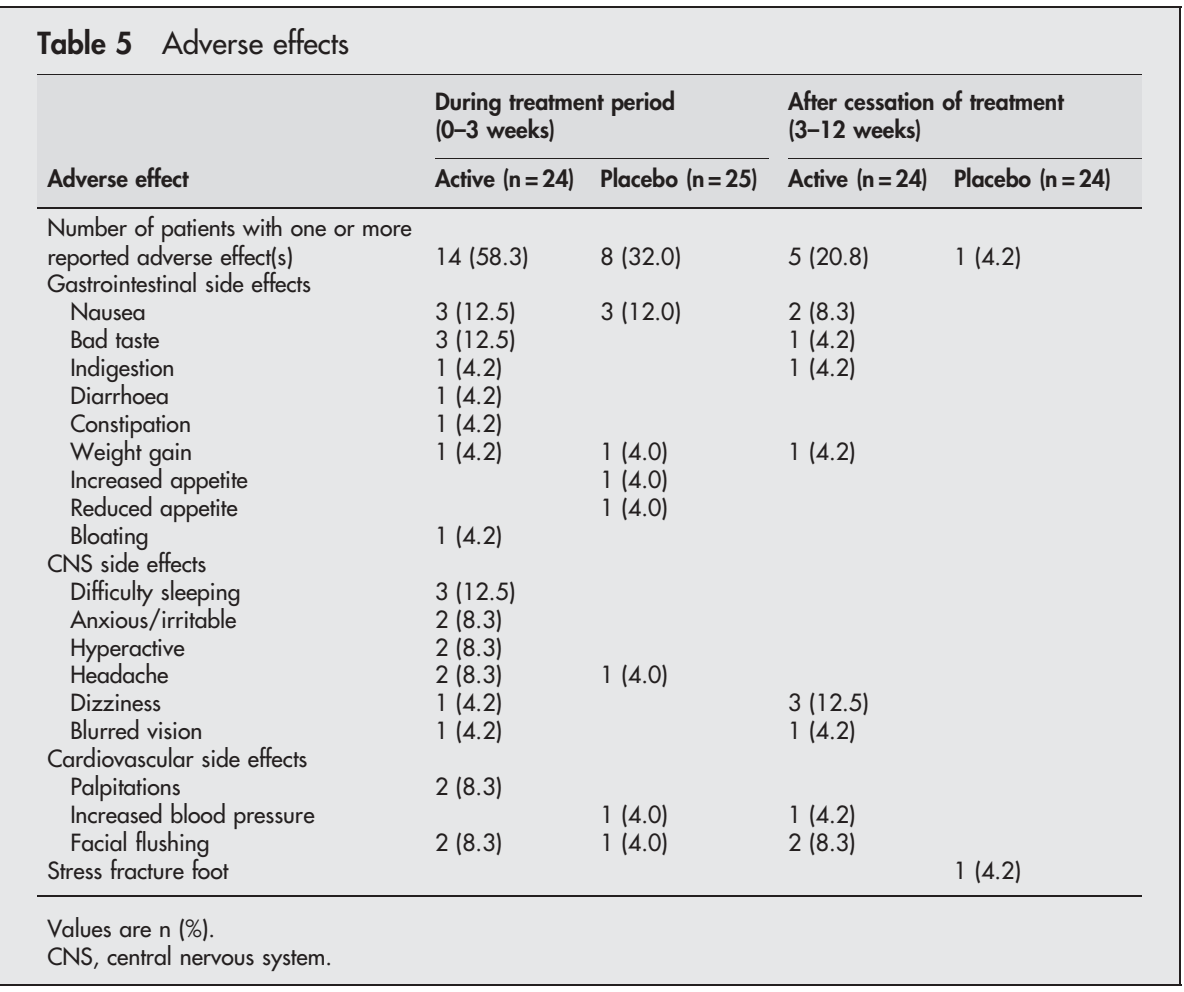


A
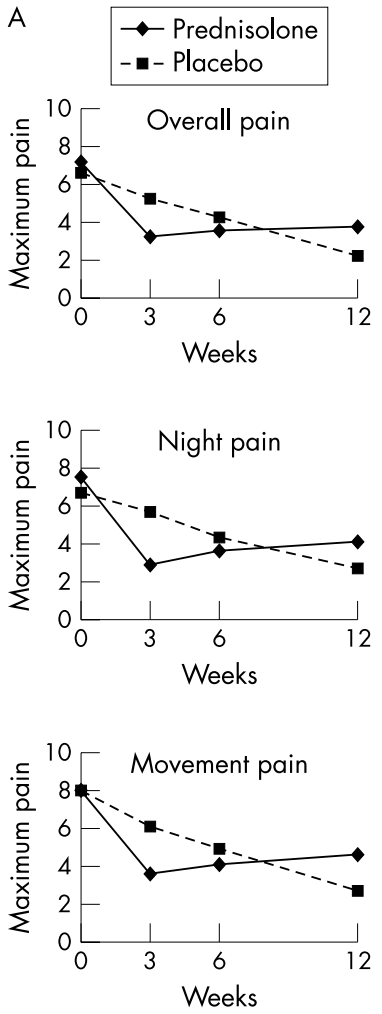

B
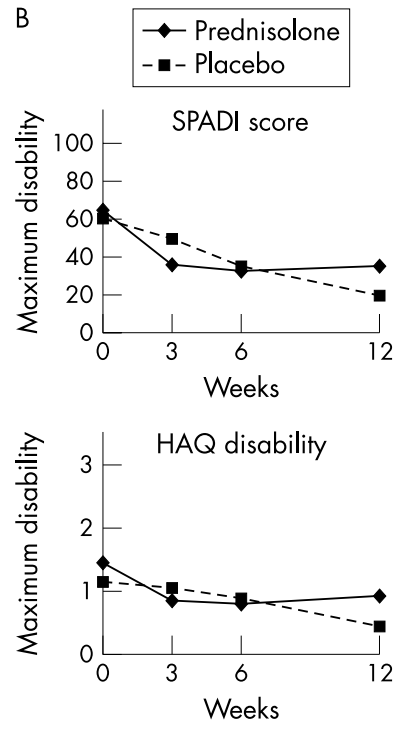
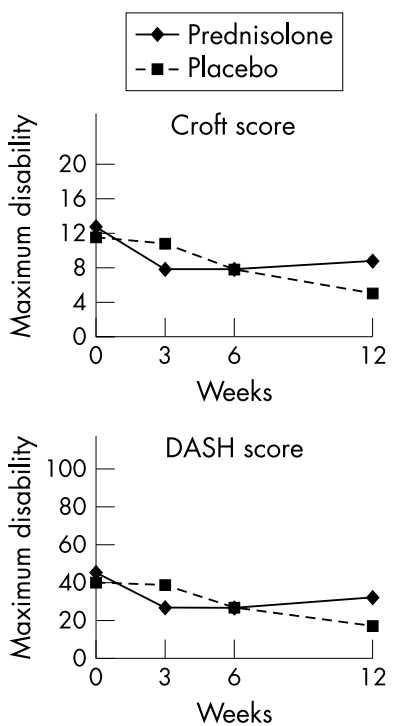

C
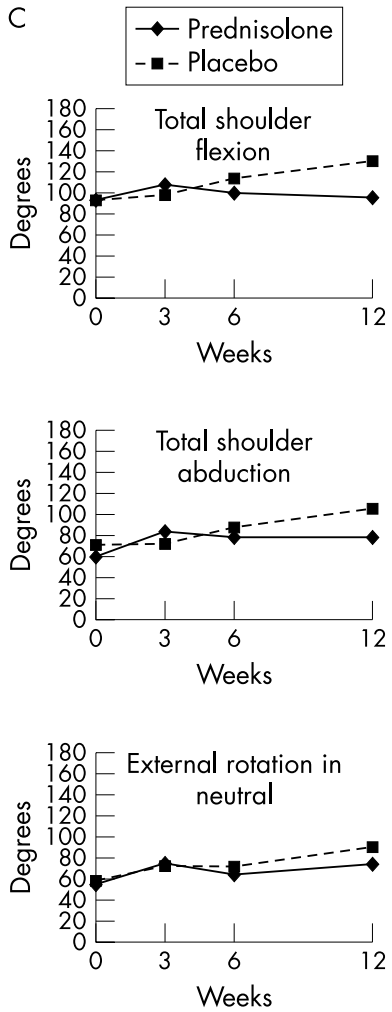

Figure 2 Graphical display of results: (A) pain; (B) disability; (C) range of active motion.

the benefit in the prednisolone group was maximal at three weeks, after which the participants either remained stable or deteriorated somewhat. In contrast, there was a small improvement in the placebo group at three weeks, after which the participants continued to improve at each follow up, with maximum improvement at 12 weeks.

More participants in the active group than in the placebo group reported adverse effects, both during treatment (14 $(58.3 \%) \vee 8(32.0 \%))$ and in the period following cessation of treatment $(5(20.8 \%) v \mathrm{l}(4.2 \%))$ (table 5$)$. There were no serious adverse effects in either group although one participant in the placebo group developed a stress fracture in the foot.

\section{DISCUSSION}

We have shown that a three week course of prednisolone $30 \mathrm{mg}$ daily in patients with adhesive capsulitis is superior to placebo in improving pain, function, and range of movement at three weeks. This confirms the finding of an early benefit of oral steroids in previous trials. ${ }^{19}{ }^{21}$ However, while there was still a trend for this benefit to be maintained at six weeks, once the prednisolone was discontinued there appeared to be diminution of benefit with respect to pain and range of movement, while functional gains were maintained at six and 12 weeks. By contrast, improvement in the placebo group increased over time, such that by 12 weeks the analysis tended to favour the placebo group.

The 12 week comparison between groups should be interpreted cautiously. While the natural history of painful stiff shoulder is for resolution of symptoms over time, the striking degree of improvement in the placebo group over 12 weeks, even when the participants with known co-interventions were excluded, was unexpected. For example, in another randomised trial in a similar, albeit slightly less severe, study population in our setting (mean severity 6.5 (SD
2.4) and 7.0 (2.0), and mean overall pain 6.04 (2.01) and 5.71 (2.08) in the active and placebo groups, respectively), comparing joint distension with saline and corticosteroid with placebo, the mean change in overall pain in the placebo group from baseline was 0.19 (1.7), 1.0 (2.4), and 2.4 (2.8) at three, six, and 12 weeks, respectively. ${ }^{34}$ In comparison, the mean change in overall pain in the placebo group from baseline in the current trial was 1.4 (2.4), 2.5 (2.7), and 4.2 (2.7) at three, six, and 12 weeks. Another recent trial which compared intra-articular corticosteroids, supervised physiotherapy, a combination of the two, or placebo included participants with a similar duration of symptoms (mean 20.3 to 22.1 weeks in the four treatment groups) and baseline SPADI scores (mean 61.5 to 67.3 in the four groups) to those of the current trial. ${ }^{35}$ The mean (SD) improvement in SPADI at six and 12 weeks in the placebo arm was 18.9 (5.1) and 29.4 (5.1) in comparison with 24.6 (20.5) and 38.9 (21.2) in our trial at the same time points. Possible explanations for the greater than expected improvement in the placebo group in the current trial include unidentified confounders and undisclosed receipt of co-interventions.

While prednisolone was very effective in the short term, there appeared to be a rebound effect after cessation of treatment, particularly for the measures of pain. This so called rebound effect or flare up of symptoms as a result of the sudden withdrawal of oral steroids has been described in a previous trial: Binder et al noted a recurrence of severe pain in two of seven patients and mild pain in four patients when the prednisolone was reduced but these symptoms settled spontaneously. ${ }^{21}$ It is also a well described phenomenon when treating other disorders, such as rheumatoid arthritis. ${ }^{36}$

Our data also suggest that three weeks might not have been an adequate course of steroid treatment. Significant improvement may have continued and increased with further active therapy or more gradual withdrawal of treatment. 
Another strategy to diminish the rebound effect of steroid withdrawal or maintain the short term gains is combination or sequential therapy. For example, while Carette et al have recently reported that a single intra-articular injection of corticosteroid with a simple home exercise programme is effective in improving shoulder pain and disability in adhesive capsulitis, supervised physiotherapy provided additional benefit. ${ }^{35}$ Further trials are needed to determine whether the rebound effect can be circumvented and whether oral corticosteroids in combination with other effective treatments provide additional and more sustained benefit.

It is important to weigh up the potential benefits and risks of the use of steroid treatment, especially in self limited disorders such as adhesive capsulitis. The adverse effects of the short course of prednisolone used in this study were minor and short lived and no serious adverse effects of oral steroids were reported in the three previous trials for painful stiff shoulder. ${ }^{19-21}$ Mild indigestion in two participants that resolved after the dosage was reduced was reported by one trial. ${ }^{21}$ However, the total sample size of these four trials was relatively small (153 participants) and a true estimate of clinically significant uncommon or rare adverse effects cannot be made from these studies. While the long term risks of oral steroids are well described and are known to be dose related, ${ }^{37} 38$ osteonecrosis has been described in patients who have only received a brief course of low dose corticosteroid therapy. ${ }^{39}$ For example, McKee et al described 15 cases of osteonecrosis of the femoral head presenting to their tertiary care university affiliated orthopaedic unit specialising in the treatment of osteonecrosis of the femoral head. These cases had all received a single short course of corticosteroids within the three years before presentation. The mean steroid dose in equivalent milligrams of prednisone was $850 \mathrm{mg}$ (range 290 to 3300), and the mean duration of drug treatment was 20.5 days (range 7 to 39 ).

Potential criticisms of our study include a relatively small sample size, although we determined a priori that we would have adequate power to determine a clinically important difference in primary outcome with 21 participants per group, if one was present. The robustness of our findings is supported by the fact that five participants assigned to the placebo group received additional treatment (including three who received prednisolone) but were included in the analysis according to their assigned treatment group.

We encountered difficulties with slow patient recruitment. We and others have previously reported difficulties in recruiting patients with adhesive capsulitis, resulting in early trial termination. ${ }^{34}{ }^{35}$ We recruited patients from the general practice referral base of the community based rheumatology practices of three investigators and we believe that our sample is representative of those patients encountered in community care. Further, the baseline demographic and clinical characteristics outlined in table 2 are similar to previous studies. ${ }^{34}$ In order to enhance recruitment we offered to see patients within one week of referral and we sent out frequent reminders of our study. Twenty five of 80 patients $(31.3 \%)$ assessed for eligibility had shoulder pain attributable to causes other than adhesive capsulitis, suggesting that general practitioners are poor at recognising this clinical entity or they were taking advantage of the short waiting time for their patients to be seen. We believe that other methods to enhance recruitment, such as advertising for volunteers, would have increased the proportion of ineligible patients screened.

\section{Conclusions}

We have demonstrated that a short course of prednisolone for adhesive capsulitis is highly effective in the short term.
Further research should be directed towards determining ways of prolonging its effect by either lengthening the duration of treatment or tapering the dose (without concomitantly increasing the risk of toxicity), or considering treatment combinations or sequential treatments.

\section{Authors' affiliations}

R Buchbinder, J L Hoving, Monash Department of Clinical

Epidemiology, Cabrini Hospital and Monash University Department of Epidemiology and Preventive Medicine, Melbourne, Australia

S Green, Australasian Cochrane Centre, Monash Institute of Health

Services Research, Melbourne

S Hall, Department of Medicine, Monash University

A Forbes, Department of Epidemiology and Preventive Medicine,

Monash University

P Nash, Rheumatology Research Unit, Nambour, Queensland, Australia

\section{REFERENCES}

1 Anton H. Frozen shoulder. Can Fam Phys 1993;39:1773-7

2 Lundberg B. The frozen shoulder. Acta Orthop Scand 1969;119(suppl):5-59.

3 van der Windt DA, Koes BW, de Jong BA, Bouter LM. Shoulder disorders in general practice: incidence, patient characteristics, and management. Ann Rheum Dis 1995;54:959-64

4 Duplay S. De la peri-arthrite scapulo-humerale et ces raideurs de l'epaule qui en sont la consequence. Arch Gen Med 1872;20:513.

5 Codman EA. The shoulder. Boston: Thomas Toddog, 1934

6 Neviaser JS. Adhesive capsulitis of the shoulder: a study of the pathological findings in periarthritis of the shoulder. J Bone Joint Surg 1945;27:21 1-22.

7 Reeves B. The natural history of the frozen shoulder syndrome. Scand J Rheumatol 1975;4:193-6.

8 Neviaser TJ. Adhesive capsulitis. Orthop Clin North Am 1987; 18:439-43.

9 Grey RG. The natural history of "idiopathic" frozen shoulder. J Bone Joint Surg Am 1978;60:564.

10 Hazleman BL. The painful stiff shoulder. Rheumatol Phys Med 1972;11:413-21.

11 Clarke GR, Willis LA, Fish WW, Nichols PJ. Preliminary studies in measuring range of motion in normal and painful stiff shoulders. Rheumatol Rehab 1975; 14:39-46.

12 Binder Al, Bulgen DY, Hazleman BL, Roberts S. Frozen shoulder: a long-term prospective study. Ann Rheum Dis 1984;43:361-4.

13 Lloyd-Roberts GC, French PR. Periarthritis of the shoulder. A study of the disease and its treatment. BMJ 1959;ii:1569-72.

14 Simmonds F. Shoulder pain with particular reference to "frozen" shoulder. $J$ Bone J Surg Br 1949;318:426-32.

15 Green S, Buchbinder R, Glazier R, Forbes A. Systematic review of randomised controlled trials of interventions for painful shoulder: selection criteria, outcome assessment, and efficacy. BMJ 1998;316:354-60.

16 Coventry MB. Problem of painful shoulder. JAMA 1953;151:178-85.

17 Sigler JW, Ensign DC. ACTH and cortisone in the treatment of the shoulderhand syndrome. Ann Rheum Dis 1951;10:484.

18 Ehrlich M, Carp SP, Berkowitz SS, Spitzer N, Silver M, Steinbrocker O. ACTH and cortisone in periarthritis of the shoulder ("frozen shoulder"). Ann Rheum Dis 1951; 10:485.

19 Blockey A, Wright J. Oral cortisone therapy in periarthritis of the shoulder. BMJ 1954;i:1455-7.

20 Kessel L, Bayley I, Young A. The upper limb: the frozen shoulder. Br J Hosp Med 1981;25:334-9.

21 Binder A, Hazleman BL, Parr G, Roberts S. A controlled study of oral prednisolone in frozen shoulder. Br J Rheumatol 1986;25:288-92.

22 Gotzsche $\mathbf{P}$, Johansen $\mathrm{H}$. Meta-analysis of short-term low dose prednisolone versus placebo and non-steroidal anti-inflammatory drugs in rheumatoid arthritis. BMJ 1998:316:811-18.

23 Altman D, Dore C. Randomisation and baseline comparison in clinical trials. Lancet 1990;335:149-53.

24 Williams JW, Holleman DR, Simel DL. Measuring shoulder function with the shoulder pain and disability index. J Rheumatol 1995;22:727-32.

25 Roach KE, Development of a shoulder pain and disability index. Arthritis Care Res 1991;4:143-9.

26 Heald SL, Riddle DL, Lamb RL. The shoulder pain and disability index: the construct validity and responsiveness of a region-specific disability measure. Phys Ther 1997;77:1079-89.

27 Croft P, Pope D, Zonca M, O'Neill T, Silman A. Measurement of shoulder related disability: results of a validation study. Ann Rheum Dis 1994;53:525-8.

28 Hudak PL, Amadio PC, Bombardier C. Development of an upper extremity outcome measure: the DASH (disabilities of the arm, shoulder and hand) [corrected]. The Upper Extremity Collaborative Group (UECG). Am J Indust Med 1996;29:602-8.

29 Fries J, Spitz P, Young D. The dimensions of health outcomes: the health assessment questionnaire, disability and pain scales. J Rheumatol 1982;9:789-93.

30 Ramey D, Raynauld J, Fries J. The health assessment questionnaire 1992: status and review. Arthritis Care Res 1992;5:119-29.

31 Ware J, Sherbourne C. The MOS 36-item short-from health survey (SF-36) Med Care 1992;30:473-83. 
32 Green S, Buchbinder R, Forbes A, Bellamy N. A standardized protocol for measurement of range of movement of the shoulder using the Plurimeter- $V$ inclinometer and assessment of its intrarater and interrater reliability. Arthritis Care Res 1998;11:43-52.

33 Vickers AJ, Altman DG. Analysing controlled trials with baseline and follow up measurements. BMJ 2001;323:1123-4.

34 Buchbinder R, Green S, Hall S, Lawler G, Forbes A. Arthrographic joint distension with saline and steroid improves function and reduces pain in patients with painful stiff shoulder: results of a randomised, double blind, placebo controlled trial. Ann Rheum Dis 2004;63:302-9.

35 Carette S, Moffet H, Tardif J, Bessette L, Morin F, Fremont P, et al. Intraarticular corticosteroids, supervised physiotherapy, or a combination of the two in the treatment of adhesive capsulitis of the shoulder. Arthritis Rheum 2003;48:829-38
36 Van Gestel AM, Laall RFJM, Haagsma CJ, Van der Putte LBA, Van Riel PLCM. Oral steroids as bridge therapy in rheumatoid arthritis patients starting with parenteral gold. A randomised double-blind placebo controlled trial. Br J Rheumatol 1995;34:347-51.

37 Walsh L, Wong CA, Oborne J, Cooper S, Lewis SA, Pringle M, et al. Adverse effects of oral corticosteroids in relation to dose in patients with lung disease. Thorax 2001;56:279-84

38 Saag K, Koehnke R, Caldwell JR, Brasington R, Burmeister LF, Zimmerman $B$, et al. Low dose long-term corticosteroid therapy in rheumatoid arthritis: an analysis of serious adverse events. Am J Med 1994;96:115-23

39 McKee M, Waddell JP, Kudo PA, Schemitsch EH, Richards RR. Osteonecrosis of the femoral head in men following short-course corticosteroid therapy: a report of 15 cases. CMAJ 2001;164:205-6.

\section{Clinical Evidence-Call for contributors}

Clinical Evidence is a regularly updated evidence based journal available worldwide both as a paper version and on the internet. Clinical Evidence needs to recruit a number of new contributors. Contributors are health care professionals or epidemiologists with experience in evidence based medicine and the ability to write in a concise and structured way.

\section{Currently, we are interested in finding contributors with an interest in} the following clinical areas:

Altitude sickness; Autism; Basal cell carcinoma; Breast feeding; Carbon monoxide poisoning; Cervical cancer; Cystic fibrosis; Ectopic pregnancy; Grief/bereavement; Halitosis; Hodgkins disease; Infectious mononucleosis (glandular fever); Kidney stones; Malignant melanoma (metastatic); Mesothelioma; Myeloma; Ovarian cyst; Pancreatitis (acute); Pancreatitis (chronic); Polymyalgia rheumatica; Post-partum haemorrhage; Pulmonary embolism; Recurrent miscarriage; Repetitive strain injury; Scoliosis; Seasonal affective disorder; Squint; Systemic lupus erythematosus; Testicular cancer; Varicocele; Viral meningitis; Vitiligo However, we are always looking for others, so do not let this list discourage you.

\section{Being a contributor involves:}

- Appraising the results of literature searches (performed by our Information Specialists) to identify high quality evidence for inclusion in the journal.

- Writing to a highly structured template (about 2000-3000 words), using evidence from selected studies, within 6-8 weeks of receiving the literature search results.

- Working with Clinical Evidence Editors to ensure that the text meets rigorous epidemiological and style standards.

- Updating the text every eight months to incorporate new evidence.

- Expanding the topic to include new questions once every 12-18 months.

If you would like to become a contributor for Clinical Evidence or require more information about what this involves please send your contact details and a copy of your CV, clearly stating the clinical area you are interested in, to Claire Folkes (cfolkes@bmigroup.com).

\section{Call for peer reviewers}

Clinical Evidence also needs to recruit a number of new peer reviewers specifically with an interest in the clinical areas stated above, and also others related to general practice. Peer reviewers are health care professionals or epidemiologists with experience in evidence based medicine. As a peer reviewer you would be asked for your views on the clinical relevance, validity, and accessibility of specific topics within the journal, and their usefulness to the intended audience (international generalists and health care professionals, possibly with limited statistical knowledge). Topics are usually 2000-3000 words in length and we would ask you to review between 2-5 topics per year. The peer review process takes place throughout the year, and our turnaround time for each review is ideally 10-14 days.

If you are interested in becoming a peer reviewer for Clinical Evidence, please complete the peer review questionnaire at www.clinicalevidence.com or contact Claire Folkes(cfolkes@bmigroup.com). 